\title{
An Assessment of the Quality Service Provided to Children with Special Education Needs in Zambian Primary Schools
}

\author{
Chila Carolyne ${ }^{1}$ and Harrison Daka $(\mathrm{PhD})^{2}$ \\ ${ }^{I}$ Department of Educational Management. University of Zambia in collaboration with Zimbabwe Open University, Zambia \\ ${ }^{2}$ Department of Educational Administration and Policy studies, University of Zambia, Lusaka, Zambia
}

\begin{abstract}
The study was looking at an assessment of the quality service provided to children with special education needs marginalized children in Zambian primary schools. Its main objectives were; to find out how teachers handle children with special education needs and the strategic plan school administrators have put in place in providing quality service to children with special needs. The study was a purely qualitative and employed a descriptive design. It targeted all primary school administrators and teachers in primary schools in Lusaka district. Data was collected using interviews (open ended questions). The collected data was analyzed using thematic analysis and the results were as follows: teachers handled learners with special needs by giving them special attention, this was done in different ways depending on the attention the teacher wanted. The study also revealed that most of the teachers made sure that the learners with special needs were always put in front of the classroom in order for easy and proper guidance. The study further revealed that the best strategy that most of the school administrators used was motivation. Teachers were motivated by being recognized by the administration through giving of prizes to teachers who had improved slow learners capabilities. The study recommended that assessments and screening for learning disabilities should be carried out in order to identify learners with learning challenges and be able to meet their need.
\end{abstract}

Key words: Children with special needs, strategies, inclusiveness, quality service.

\section{INTRODUCTION}

$\mathrm{E}$ ducation is an important investment that a country can make and enhancing accessibility to educational services is significant in the development of a nation (Farrant, 2019; Mulenga-Hagane, Daka and Kanchebele-Sinyangwe, 2020).). This is because education positively affects socio-economic behavior such as productivity, living standards, health and demographic characteristics of any population. Likewise, it opens infinity of possibilities for society that would otherwise be denied namely; a better chance to lead healthy and productive lives, building strong and nurturing families, participating fully in civic affairs of their communities, molding morals and values, creating culture and shaping history. It is a solid foundation for progress and sustainable development, an inherent human rights and critical step towards dismantling the gender discrimination that threatens all other rights catalyzing freedom and democracy within borders and extending its reach as an agent of international peace and security (United Nations Children's Fund (UNICEF), 2016). It's therefore, societal obligations to make the provision of education to all people according to the nature of their individual's needs and capacity.

Throughout the world, children with special educational needs (CSEN) and many others who experience difficulties in learning are often marginalized and sometimes excluded from school systems. Researchers (Kalabula, 2007; MoGE, 2011; Serpell and Jere-Folotiya, 2011; Hamaleke, Daka and Mphande, 2020) pointed out that 8 to 10 percent of the children in Zambia are still in this category and hence require active intervention and specialized services because they are affected by biological, environmental and psychosocial conditions that can limit their cognitive development. These kinds of children frequently leave school with few qualifications and are much more likely to become unemployed or economically inactive. Their parents also experience high levels of stress. They face different forms of social neglect and exclusion which affect them in different ways due to factors such as the kind of disability they have, where they live and the culture or class to which they belong (United Nations Children's Fund, 2013; Daka, Chilala, Hamatanga, Chirwa, Mumba, Kaoma, and Chikopela, 2021) ). Therefore, there is need to overcome the barriers to inclusion and participation that vulnerable members of society face because if they are not adequately supported, not only will the development of the child suffer but the family unit as a whole can be placed under considerable strain.

Looking at how important education is to the life of any person and country as a whole, the Zambian government under the Ministry of General Education saw it necessary to include children with special needs in a general education setting. This is called inclusiveness which is the integration or incorporation of children with disabilities in the mainstream in order to accommodate all children regardless of their physical, intellectual, social, emotional, linguistic competences or other needs (The United Nations Educational Scientific and Cultural Organization (UNESCO), 2009). Moreover, special education need children would benefit most from education alongside 
neuro-typical children in mainstream schools as opposed to special schools catering specifically for those with special needs. Nabuzoka and Ronning (1997) further suggested that inclusive schooling decreases the shame experienced in isolated schooling and also enables able-bodied pupils to be more receptive to their disabled colleagues such as those suffering from epilepsy, cerebral palsy, a child with vision difficulties, those at risk for a disability because of environmental conditions, depressed immune system or chronic asthma, Attention Deficit Hyperactivity Disorder as well as other categories of disability which may exhibit challenging behaviors that affect the learning process. Hence, implementing inclusive education is high on the agenda of many countries though the policy and legal legislations are approached from differing historical and structural perspectives.

With the growing number of children who have learning disabilities being included in the general education classroom, the Zambian government adopted and implemented various pieces of legal frameworks and policies aimed at enhancing or providing legal protection of children with disabilities, promotion of their human rights, social activities, equal access to education and other community services among others (Matafwali, 2007). These policies and legal frameworks include the following; Education Act (1966), National Policy on Education (MOE, 1996), the Persons with Disabilities Act No. 6 of 2012 and the Pupils with Special Educational Needs Policy, Zambia National Campaign to Reach Disabled Children (ZNCRDC), the Salamanca statement and framework for action on special needs education (Serpell and Jere-Folotiya, 2011), among others serve as a guide to practitioners and relevant authorities. Such kinds of legislations and policies are now supposed to be executed by school managers and teachers who are found with children with special needs on a daily basis in ensuring that they are provided with quality service.

Despite the above mentioned policies, (UNESCO, 1994; Serpell and Jere-Folotiya, 2011) both acknowledge the difficulties faced by inclusive schools in achieving education for all children especially those severely disadvantaged and disabled. Therefore, implementing education services for children with special education needs in Zambia comes with challenges such as lack of a child database, nature of disability and distance from school just to mention a few. This should not be left without a solution. School managers have to come up with strategies on how quality services should be provides to such kind of children for the realization of their full potential. Trained teachers also have a crucial role to play in supporting inclusion in mainstream classrooms. For example, they can provide one-to-one help to children in the classroom and provide guidance on the best position for a child in the classroom because those with special needs have their own unique strengths and weaknesses. Therefore, this study was centred on how teachers handle children with special needs and the measures school managers had put in place to make sure that quality service is provided to such kind of learners.

\section{Statement of the Problem}

Education is a tool which provides people with knowledge, skill, technique and information, enables them to know their rights and duties toward their family, society as well as the nation. It develops the capabilities to fight against injustice, violence, corruption and many other bad elements so that the society can be smoothly run. This is the reason why the Ministry of Education in Zambia introduced what is called Inclusive Schooling Program (INSPRO) to allow children with special educational needs to remain in regular schools. The Zambian Government and the Ministry of General Education's stance on inclusion has been influenced by the Salamanca Statement and Framework (UNESCO, 1994). Thus, the Zambian government adopted certain policies such as Educating Our Future that stipulates equal opportunities, social justice and protection of basic human rights, increasing access, participation, and achievement for all learners in general education settings with emphasis on those at risk of marginalization and exclusion. Despite that, studies (Abbott and McConkey, 2006. World Bank, 2004, Oigay and vuran 2015) shows that children with special needs lack quality education services as they are still being stigmatized and discriminated. If this trend continues, they might not realize their full potential in life. Hence, the study came up with strategies that school managers and teachers can put in place to ensure quality service to CSEN.

\section{Purpose of the Study}

The purpose of this study is to find out the strategies school managers and teachers play in ensuring that quality service is provided to children with special needs.

\section{Research Objectives}

The study had the following objectives which guided the research:

1. To find out how teachers handle children with special education needs.

2. To find out the strategic plan school managers have put in place in providing quality service to children with special needs.

\section{Significance of the Study}

It is hoped that the results of this study may help teachers and school managers to realize that children with special needs require full support to ensure that they feel part of the general membership in a school setting which in turn, will make them realize their full potential in life and access equal opportunities. It will also bring to light the challenges being faced with while implementing inclusive education for learners with disabilities. It will further add value to the body of knowledge concerning the children with special needs and the quality services they receive from teachers and school 
managers in inclusive education. Moreover, it is anticipated that what will come out of this study, will help policy makers, political leadership, the education community in Zambia and other stakeholders such as non-governmental organizations in enacting necessary measures or actions for the advancement of education for children with special needs directed at achieving quality education, learning and social inclusion in a general education setting.

\section{THEORETICAL FRAMEWORK}

The study will employ what is called social inclusion and exclusion model by Cunningam and Flemming (2009). The understanding of the Social inclusion and exclusion model is that the individuals who are marginalized are excluded from meaningful and effective participation in their daily school activities. This is a clear indication that they are not provided quality services. Hence, the model of social inclusion entails that people with disabilities should be provided with the much needed support and social services within their own schools rather than providing them with services in special settings. The ones to do that within their own schools are school managers and teachers. Doing so, improves the terms of participation in society for people who are disadvantaged on the basis of their disability through enhanced opportunities, access to resources, voice and respect for rights. Thus, as a political response to the exclusion challenge, social inclusion is thus a more deliberate process of encompassing and welcoming all persons and embracing greater equality and tolerance. This model takes into account six aspects namely; (1) teaching methods, (2) skills of handling learners with special needs, (3) medium of communication, (4) lack of acceptance by institutions, (5) emotional life and (6) learning materials as areas in which such kinds of children face in an inclusive setting.

Teaching methods is where a teacher uses appropriate teaching methods if learners are to be included in the education system and avoid exclusion. Handling of learners also need to be put into consideration. In this case, teachers need to have appropriate skills if such learners are to perform well academically. Such skills include allowing learners with special needs to sit in front and where there is light especially learners with hard of hearing and short sight. When talking about communication, educators are supposed to use appropriate gestures such as speaking louds and other symbols so that children with special education needs in inclusive setting can grasp what is being taught. By doing so, the provision of quality services to such kinds of children is assured.

Acceptance in different schools by teachers and administrators is another area of concern with this model. For instance, most teachers and administrators have not embraced the change from special education to inclusive education which makes it difficult for learners with special needs to fit in inclusive setup because they are not included in most of the school programs and budgets. Sometimes these kinds of children even face rejection during enrollment time. This plays a big role in ensuring that children with special needs are excluded and in case they are included, they are likely to face a lot of stigmatization and discrimination. Therefore, it is important in an inclusive education set up to embrace children with special needs as a way of providing a quality service to them because they will feel at home.

Emotional life was also emphasized in this model if learners were to enjoy in general education setting otherwise if not well considered, they might exhibit certain behaviors such as low self-confidence and also frustration which can play a big part in poor academic performance. Lastly but not the least, the pioneer of this social inclusion and exclusion model considered teaching materials as important to children with disabilities. Learners should be given materials that will enable them to fit in an inclusive set up otherwise they will just register their presence in classroom without participating and benefiting from what is being taught. Therefore, it is important to put up a proper strategic plan so that such kinds of children can receive the needed quality services. The model suits well for this study as it has touched part for the teachers and school managers as well as children with special needs in a general education setting.

\section{METHODOLOGY}

A qualitative method was used in this study because the research had an interactive in-depth interviews with school managers on strategies they have put in place to provide quality service to children with special needs, teachers on how they handle such type of children and the problems they face when doing so in a general education setting. In qualitative research, feelings and insights are considered important as it emphasizes words rather than quantification in the collection and analysis of data. This study used descriptive. This was more applicable to addressing the needs of the marginalized whilst promoting acts of assistance, prioritize fairness and human rights to such people. It also allows researchers to bring about social change and equity to those in need and transform lives of the disadvantaged such as children with special education needs (Creswell, 2014; Chipindi, Serenje Chipindi and Daka, 2021).

A total of four school managers from four primary schools were interviewed. School managers gave the researcher information about strategies they have put in place to provide quality service to children with special needs. Twelve primary teachers (three from each school) were also be sampled. These provided data on how children with special needs are handled. Six parents to the CSENs also were interviewed to get views on how they perceived the learning process of their children. Lastly and not the least views were taken from the six children also to learn how they perceived the environment.

Permission were granted by the Lusaka district education board officer. It is at this stage that a researcher was given an introductory letter to present to school managers so that a 
research can be conducted in the mentioned district. At school level, the researcher had seek permission from school managers who are also part and parcel of participants to go ahead with data collection. This study used two research instruments namely; interviews and open ended questionnaires.

Semi-structured interviews were conducted with a purpose of obtaining descriptions of the life world of the interviewee with respect to interpreting the meaning of the described phenomena. This required the researcher to set out the questions as open ended questions which allow the interviewees to have the possibilities of going beyond the question of a researcher. The researcher was in charge of the interview process but participants were given free hand to discuss, answer questions freely and express themselves without being interrupted. With semi-structured interviews, some answers lead to further questions which meant to ascertain validity and authenticity. Giving the participants the freedom to talk freely and openly, this provided the researcher with in-depth information on the research topic as they relate own experiences to external systems.

Questionnaires were given to teachers to find out more about how the handle learners with special education need, the problems they encounter as they carry out their duties and probably the solutions to such problems. The questionnaire also had a part which requested for teacher demographic information such as gender, age as well as their level of education.

The researcher utilized qualitative thematic analysis to extract common themes, patterns and relations. During this process, interview transcripts were hand-coded to identify conceptual themes that were clear within both the research literature and within the data. All audio recordings were transcribed verbatim, irrespective of how intelligible the transcript may have been, it was read back. The interviews recordings were then transcribed and coded to categories key themes and identify patterns. Each theme was analyzed to gain a deeper understanding of the participant's perceptions and opinions.

\section{RESULTS}

\section{How Teachers Handle CSEN}

Participants cited a number of measures which they thought could help improve the teaching of learners with special educational needs such as the following below:

One of the teacher said:

The slow learners are given apple time by the teachers always once their friends have submitted their works, she went further to say other slow learners are quick to finish whenever work has been given to them but that does not mean they have done the correct thing, it was from this affirmative that she said the handle she learners by putting them in front of the class room once one has been identified, for the fast learners they are usually advised to slow the speed on their work.

One other teacher pointed out that:

It is mandatory for every teacher who has leaners with special needs to give such leaners a superior type of attention in order to allow them compete with other learners.

It was also noted that most of the teachers who had learners with special attention adhered to such administrative directives.

One teacher said:

Giving special attention to learners with special needs has really helped the results of the class owing to the fact that teachers tend to know what they ought to do if they were to help a slow learner.

Another teacher said:

Since the day I start giving special attention to the learners who needed special attention after identifying them there academic performance has improve.

In addition to what the teachers above stated, the other teacher added that:

Those leaners with special need who were on different medications due to their failing health, the teachers organized homework's for them and special attention was given once they came back to school.

Most of the teachers said they use facilitating learning.

Most of the times am the one who facilitate the teaching of my learners in class, this is because of the them are slow learners, hence am forced to always facilitate the learning process

One of the teacher said:

as a teacher, it is always important to set goals or objective that are achievable by both the fast learners and the slow learners hence it is always important to make sure that the slow learners are a priority when setting goals.

It was also observed that most of the teachers who had identified learners with special needs in there different classes come up with other simple objectives which looked at the improvement of the slow learners due to their different disabilities.

One teacher emphasized by saying:

Every time I prepare my lesson plan with different objectives, I always consider other objectives to be 
simpler for the slow learners to easily understand and this has helped to improve their performance during and after their grade 7 exams.

It was stated that group work has helped some slow learners to put them in small groups which usually help the slow learners to be a bit active. This is what was pointed out by one teacher.

Group work the best strategy teachers used in order to curb the difference or the gap between slow learners and faster learners in different classrooms. Sometimes I do pair child specifically for slow learners" and that all classes were given specialized teachers. Children with special education need have the fears of interactions and relationships amongst learners in a general set up. In short, they live in fear of other learners. This is pointed out in one participant's response that,

\section{"In the classroom there is a lot of gossip, jealousy and pretending which makes one uncomfortable in this environment. There is also stealing and fighting over small issues".}

It is evident that the classroom in this case, is the place where the fittest survive. It is not a welcoming and friendly environment to most of the learners. It poses a threat to effective communication between learners. In as much as inclusion is desired in the classroom, this situation promotes exclusion and hampers learning. It is evident from the data that interaction and relationships among learners in the classroom are not good.

One participant stated that, "Learners treat each other badly, rudely if you cannot cope with the learning task, and will tease you and make fun of you".

\section{How School Administrators Provide Quality Service to CSEN}

Motivation was one factor that school administrators mentioned as a strategy to help teacher provide quality service to CSEN. One of the head teachers said most teachers are motivated by the school through the giving of awards by the school management over the good which a certain teacher has showcased.

We do give awards to deserving teachers through the high pass rate in his or her class.

Another head teacher also added by saying:

At this school we encourage teacher by giving them prizes once ones class has performed well during and after the exam on the number of learners who have made it to the other grade.

Slow learners benefited mostly from remedial instruction. Remedial instruction for slow learners refers to two types of programs, eliminating ineffective habits and unwholesome attitudes and re-teaching skills which have been incorrectly learned. This refers to remediation of defects (GRZ, 2007). Teaching for the first time those habits, skills and attitudes which have never been learned but should have been and which are needed by such children. This refers to developmental teaching or developing increased competence. Other head teacher stated:

At our school I encourage clinic teaching was the other strategy they used for learners who were not improving in a given term. The clinical teaching was the strategy initiated specifically for those who did not know how to read and write.

Parents' views about the Learning Environment

Parents had similar views on the learning environment for their children. One parent stated:

\begin{abstract}
When my son comes back from school she complains of the sanitation that at break time the abled learners access the toilets faster and leave them dirty. She further lamented that some teachers are not so friendly to her.
\end{abstract}

Furthermore, one parent added:

I appreciate the way my child is received and taken care of at that school. My child is always given time to finish work and more attention is given to him. Extra work is also provided to be done at home.

\section{Children with Special Education Needs' views}

Children with special education needs' views about the learning environment did not differ with what parents and teachers said. One child said:

Am given special attention in class. Whenever the teacher asks a question, am first asked to give an answer before anyone else. At first it gave me pressure but now am used and I learn a lot.

Another child also added:

Our fellow learners in class are very supportive. They help me a lot in group work to understand things better.

Promoting a positive classroom climate which can have a powerful and constructive effect on learners' engagement and learning, is one of the solution or strategies put in place to provide quality service to children with special need. Not only that but also encouraging learner interactions. This has a direct effect on their sense of fulfillment and their persistence and retention. The more academically and socially connected learners feel, the more likely they are to persist. Hence, school managers should help support this kind of engagement by providing opportunities for learners to meet and connect with each other. This includes helping them learn each other's names and stretching their comfort zones by having them move to different seats and sit with different small groups. The benefits are far reaching from increasing attendance to building a positive rapport and respect among all those in class. The goal is to make them have thoughtful interactions 
and conversations with peers from different backgrounds and life experiences. Therefore, the type of classroom climate create and the teaching techniques used can produce an environment that either supports or impedes the diverse pupils.

\section{DISCUSSION}

\section{How Teachers Handle CSEN}

The findings showed that teachers handled learners with special needs by giving the learners special attention. This was done in different ways depending by the attention the teacher wanted. The study revealed that most of the teachers made sure that the learners with special needs were always put in front of the classroom in order for easy and proper guidance. The findings show that most of the teachers made sure that separate and simple objectives were made as a deliberate move to help the learners with special needs and this encouraged the learners to work hard and improve their academic performance. The findings also showed that teachers handled learners with special needs by putting them into a certain group. There is need for small group work blended with some individualized instruction. This is consistent with the findings of Gillies (2016) who confirmed that cooperative learning has the potential to improve the quality of learning.

In school verbal instructions and explanations are quite important. Many of the slow learners have retarded speech: articulation, vocabulary, brief sentence, grammatical errors. Emotional reluctance is the chief reason for their backwardness of expression. They need a great deal of speech stimulation through play, and through talking to adults, listening to them. Expression is often lacking in order, sequence and selectivity. These children are also poor in, remembering messages and listening to instructions, stories and other forms of spoken words. Attention therefore, should be given to listening and reproduction skills. Poor language may be due to several factors: poor background of speech and language at home, a limited background of experience, emotional and social factors and the limitation of the slow learner's thinking capacity.

These children can develop their language by talking about what they have seen or done, by discussing what they are going to do and how they are going to do it. These are most effective for they evoke stronger feelings of enthusiasm and interest and therefore expression. The teacher should guide and stimulate the child's thinking about his experiences, what they noticed while concerning to school, climbing tree, making and explaining scrap books, explaining what they learned in television, role playing in a drama in school, listening to stories, puppetry, allowing the puppets to speak to each other, conversation among peer groups. This is in agreement with the studies done by Daka, Banda and Namafe (2020) and Daka, Namafe and Mukwato - Katowa (2019).
The fact that many children do acquire a better form of speech for use in school does suggest that progress can be made.

\section{How School Managers provide Quality Service CSEN}

The study revealed that the best strategy that most of the school administrators used was motivation. Teachers were motivated by being recognized by the administration through giving of prizes to teachers who had improved slow learners capabilities after doing a self-evaluation on every teacher who handled learners with special needs, school parties were organized specifically for such events. It was also noted that most of the parents pointed out particular teacher in terms of appreciating their efforts through the PTA a meetings to encourage them to continue working hard and this motivated them regardless of their salaries not meeting their daily needs. This has proved to be a workable method as seen from the study done by Daka, Chipindi, Phiri, Mulenga, Mvula and Chirwa (2021). The other strategy that was used by the teachers is learner centered teaching, this was used because it alters the presentation of content to circumvent a student's fundamental weakness or deficiency. According to Anfara (2015) and Daka and Changwe (2020) learner centered teaching recognizes content, transmits through alternate modalities (pictures versus words), and supplements it with additional learning resources and activities (learning centers and simulations, group discussions and co-operative learning). The study revealed that this involved modifying an instructional technique by including a visual representation of content, by using more flexible instructional presentations (films, pictures, illustrations), or by shifting to alternate instructional formats (self-paced texts, simulations, experience-oriented workbooks).

\section{CONCLUSION AND RECOMMENDATIONS}

\section{Conclusion}

On the first objective, the findings show that most of the teachers made sure that separate and simple objectives were made as a deliberate move to help the learners with special needs and this encouraged the learners to work had and improve their academic performance. The findings showed that teachers handled learners with special needs by giving the learners special attention, this was done in different ways depending by the attention the teacher wanted. This study established the presence of learners with learners with special needs in the schools of study. Learners with reading, writing, mathematical difficulties, hyperactivity, attention deficit were spotted by teachers within their classrooms.

On the second objective, the other strategy that was used by the teachers is learner centered teaching. This was used because it alters the presentation of content to circumvent a student's fundamental weakness or deficiency. The study revealed that the best strategy that most of the school administrators used was motivation. Teachers were motivated by being recognized by the administration through giving of prizes to teachers who had improved slow learners capabilities 
after doing a self-evaluation on every teacher who handled learners with special needs, school parties were organized specifically for such events. The study revealed learning skills as a strategy which increased the learning skills by teaching note-taking, outlining, and listening. These skills are acquired through observation by higher ability students, but they must be specifically taught to slow learners. It was evident from the findings of the study that participating teachers knew what they needed to do in their teaching in order to make their classroom much more interactive and yet they did not do much to translate their theoretical knowledge into practice. What they did and what they said did not match, as evidenced from the findings.

\section{Recommendations}

The study had the following recommendations to be considered for implementation:

- Government through the Ministry of General Education should ensure there is in-service training for teachers so that they acquire the necessary understanding of learners with learning disabilities and how best to teach them in inclusive classroom and Continuous Professional Development (CPD) should be strengthened to sensitize teachers on learning disabilities and provide strategies for teaching them in inclusive classrooms.

- Assessment and screening for learning disabilities should be carried out in order to identify learners with learning disabilities and be able to meet their need

- Teachers should avoid any kind of competition or comparison between normal or gifted students and slow learners. Motivation among teachers should be supported by school administrations. Need to involve of parents at every stage on a child with special needs.

- Mostly use group strategy formula in teaching to encourage CSEN learn from others.

- During break time, other learners should allow the CSEN to equally have early access to bathrooms.

\section{REFERENCES}

[1] Abbot, S \& McConkey, R. (2006). Barriers to Social Inclusion as perceived by People with Intellectual Disabilities. Journal for Intellectual Disabilities, 10:275.

[2] Anfara, T. (2015). Qualitative Analysis on Stage: Making the Research Process more public. Thousand Oaks, CA: SAGE

[3] Chipindi, F. M., Serenje-Chipindi, J and Daka, H. (2021). An Analysis of Epistemological Considerations in Educational Research. Journal of Lexicography and Terminology. Vol.4 (2), $105-118$.

[4] Creswell John.W., 2014. Research Design; Qualitative, Quantitative and Mixed Methods Approaches, 4th Ed, Los Angeles, Sage Publications.

[5] Cunningham, A. R.R \& Fleming, V.C. (2009) Theories of Disability: Findings from an Analysis of Textbooks on Human Behavior and Social Environment. Journal of Human behavior in Social Environment, 19: 10-25.

[6] Daka, H., Banda, S. S., \& Namafe, C. M. (2020). The Relationship Between Course Management And Examination Attrition Rates Among Undergraduate Medical Students at the University Of
Zambia. International Journal of African Higher Education, 7(1), $97-112$

[7] Daka, H. and Changwe, R. (2020). An Exploration of Education Quality in the Light of the Grade Point Average and Examination Attrition Rate. International Journal of Humanities Social Sciences and Education. Vol.7 (6), 196-207. ISSN: 23490373 (Print) \& ISSN 2349-0381 (Online).

[8] Daka, H., Chilala, M. M., Hamatanga, O. H., Chirwa, B., Mumba, A., Kaoma, C. and Chikopela, C. (2021). Averting Learner Absenteeism in Zambian Urban and Rural Primary Schools. A Case of Kalingalinga and Simweendengwe Primary Schools. Journal of Lexicography and Terminology. Vol.5 (1), 33 55.

[9] Daka, H., Chipindi, F. M., Phiri, A., Mulenga, B., Mvula, L and Chirwa, J. (2021). Administrative Mitigation Measures against Examination Attrition Rates in Tertiary Institutions: A Case of School of Education, University of Zambia. European Modern Studies Journal. Vol. 5 (3), $248-258$.

[10] Daka, H., Namafe, C. M. and Katowa - Mukwato, P. (2019). Perspectives on Teaching Approaches and the Grade Point Average Attainment of Undergraduate Medical Students at University of Zambia. International Journal of Humanities Social Sciences and Education. Vol.6 (12), 75-82.

[11] Farrant, J.S. (2019). Principles and practices of Education (5th Edit). London. Longman Publishing House Ltd.

[12] Gillies, R. (2016). Cooperative Learning: Review of Research and Practice. Australian Journal of Teacher Education. 41. 39-54. 10.14221/ajte.2016v41n3.3.

[13] GRZ. (2007). 2007 Educational Statistical Bulletin. Lusaka, Zambia: GRZ Ministry of Education.

[14] Hamaleke, B, S., Daka, H. and Mphande, F. (2020). Strategies to Overcome the Challenges faced by Weekly Boarders: A case study of Selected Day Secondary Schools in Chikankata District in Southern Province, Zambia. International Journal of Humanities Social Sciences and Education. Vol 7 (6), 175 186.

[15] Kalabula, M. D. (2007). Special Education in Zambia. Lusaka: Musumali Press, Zambia.

[16] Matafwali, B. (2007). ECCD Evaluation Report. Lusaka: UNICEF Publication.

[17] Moberg, S. (2003). "Education for all in the North and the South: Teachers' Attitudes towards Inclusive Education in Finland and Zambia." Education and Training in Developmental Disabilities 38(4), pp.417-428.

[18] MoGE. (2011). National Implementation Framework III (NIF III). Lusaka.

[19] Mulenga-Hagane, M., Daka, H. and Kanchebele-Sinyangwe, M. (2020). Learning from Change: Benefits and Implications of Distinct Primary and Secondary Schools for Education in Zambia. Malcolm Moffat Multidisciplinary Journal of Research and Education, 1 (1), 121 - 136.

[20] Nabuzoka, D \& Ronning, J. 1997. Social Acceptance of Children with Intellectual Disabilities in an Integrated School Setting in Zambia: a pilot study. International Journal of Disability and Development, Vol. 44, No. 2, pp. 105- 115.

[21] Olcay-Gül, S and Vuran, S. (2015). Children with Special Needs' Opinions and Problems about Inclusive Practices. Education and Science Vol 40 (2015) No 180 169-195.

[22] Serpell, R and Jere-Folotiya, J. (2011). Basic Education for Children with Special Needs in Zambia: Progress and Challenges in the Translation of Policy into Practice. University of Zambia, Lusaka, Zambia. Psychology and Developing Societies, 23, 2 (2011): 211-245.

[23] UNESCO. (1994). Salamanca Statement and framework for Action on Special Education Needs. Paris: United Nations.

[24] UNICEF. (2013). The state of the world's children: Children with Disabilities.

[25] UNICEF. (2016). Zambia National Budget Brief: Review of 2016 Social Sector Budget Allocations. UNICEF: Lusaka 
International Journal of Research and Scientific Innovation (IJRSI) |Volume VIII, Issue VI, June 2021|ISSN 2321-2705

[26] UNESCO. (2009). Inclusion of children and disabilities: the early childhood imperative. UNESCO Policy Brief on Early Childhood.
[27] World Bank (2004). Inclusive Education: An EFA Strategy for All Children. 